\title{
Insulin Glargine in the Intensive Care Unit: A Model-Based Clinical Trial Design
}

\author{
Jonathan G Willis ${ }^{1}$, Liam Fisk ${ }^{1}$, Normy Razak, Aaron Le Compte ${ }^{1}$, \\ Geoffrey M Shaw ${ }^{2}$, and J Geoffrey Chase ${ }^{1^{*}}$
}

${ }^{1}$ Department of Mechanical Engineering, Centre for Bio-Engineering, University of Canterbury, Christchurch, Private Bag 4800, 8054, New Zealand

${ }^{2}$ Department of Intensive Care, Christchurch Hospital, Christchurch School of Medicine and Health Science, University of Otago, Christchurch, New Zealand

*Corresponding Author: geoff.chase@canterbury.ac.nz 


\begin{abstract}
Introduction: Current succesful AGC (Accurate Glycemic Control) protocols require extra clinical effort and are impractical in less acute wards where patients are still susceptible to stress-induced hyperglycemia. Long-acting insulin Glargine has the potential to be used in a low effort controller. However, potential variability in efficacy and length of action, prevent direct in-hospital use in an AGC framework for less acute wards.
\end{abstract}

Method: Clinically validated virtual trials based on data from stable ICU patients from the SPRINT cohort who would be transferred to such an approach are used to develop a 24-hour AGC protocol robust to different Glargine potencies (1.0x, 1.5x and 2.0x regular insulin) and initial dose sizes (dose $=$ total insulin over prior 12, 18 and 24 hours). Glycemic control in this period is provided only by varying nutritional inputs. Performance is assessed as $\% \mathrm{BG}$ in the $4.0-8.0 \mathrm{mmol} / \mathrm{L}$ band and safety by $\% \mathrm{BG}<4.0 \mathrm{mmol} / \mathrm{L}$.

Results: The final protocol consisted of Glargine bolus size equal to insulin over the previous 18 hours. Compared to SPRINT there was a $6.9 \%-9.5 \%$ absolute decrease in mild hypoglycemia $(\% \mathrm{BG}<4.0 \mathrm{mmol} / \mathrm{L})$ and up to a $6.2 \%$ increase in $\% \mathrm{BG}$ between 4.0 and $8.0 \mathrm{mmol} / \mathrm{L}$. When the efficacy is known (1.5x assumed) there were reductions of: $27 \% \mathrm{BG}$ measurements, 59\% insulin boluses, 67\% nutrition changes, and $6.3 \%$ absolute in mild hypoglycemia.

Conclusion: A robust 24-48 clinical trial has been designed to safely investigate the efficacy and kinetics of Glargine as a first step towards developing a Glargine-based protocol for less acute wards. Ensuring robustness to variability in Glargine efficacy significantly affects the performance and safety that can be obtained. 


\section{$\underline{1.0 \text { Introduction }}$}

Critically ill patients often suffer stress induced hyperglycemia [1]. Hyperglycemia is associated with an increased risk of infection, myocardial infarction and mortality [2-4]. Attempting to control hyperglycemia can significantly increase the risk of hypoglycemia [5] making original promising results $[6,7]$ difficult to repeat [8-10]. The SPRINT glycemic control protocol [7] is the only published protocol to reduce both mortality and hypoglycemia. However, it requires BG measurements every $1-2$ hours. Thus, the clinical effort required is high and may not be necessary for all patients.

It is common for patients to be admitted to a High Dependency Unit (HDU) if they are not intubated or do not require extensive circulatory support. There can be a reluctance to use AGC (Accurate Glycemic Control) protocols in the HDU due to the clinical effort and relatively limited nursing resources [11], leading to a tolerance of some hyperglycemia. However, these patients are still susceptible to counter-regulatory stress responses and hyperglycemia, necessitating an effective method to transition glycemic control from critical care to less acute wards with less nursing resources and less use of intravenous lines to deliver insulin or other drugs.

Glargine is a very long acting insulin analogue used to manage Type 1 diabetes, primarily in relatively low doses (per hour) to replace basal insulin. It is administered subcutaneously and released very slowly into the blood plasma over $22-26$ hours [12]. Hence, it has potential advantages for a low intensity AGC protocol requiring only one daily administration. 
Although many studies have been carried out on the specific kinetics and dynamics of Glargine in healthy individuals, there is still insufficient data for use with in-hospital AGC protocols on highly dynamic, critically ill patients. Current studies indicate that Glargine may be up to twice as potent as regular insulin [13], which, with varying kinetics and appearance rates [14], could add significant risk in using higher doses for these patients whose insulin sensitivity can vary significantly over time compared to healthy individuals [15].

Further clinical information about the dynamics of Glargine in these patients is required to avoid unnecessary risk. Model-based control and simulation environments can be used to develop clinical protocols to safely examine different expected action profiles and efficacy of Glargine in these patients, while simultaneously providing AGC. In particular, this study develops a first model-based controller to be used in 24 hour pilot trials to assess the potential of Glargine in this cohort, and to also collect data on the issues of efficacy and kinetics while producing safe, effective AGC in a replicable fashion. This is the first example to employ model-based control to elucidate specific drug properties. 


\subsection{Methods:}

The SING (Stochastic Insulin Nutrition and Glargine) controller was developed using clinically validated virtual trials [16] on virtual patients based on retrospective clinical data. It combines the ICING (Intensive Control Insulin Nutrition Glucose) model [17] of insulinglucose pharmacokinetics and pharmacodynamics and glucose disappearance in plasma with a validated model of subcutaneous pharmacokinetics of Glargine from injection to appearance in plasma [18-20] and makes use of the stochastic forecasting used in STAR [21].

\subsection{ICING Model:}

Five differential equations describe the glucose-insulin pharmacokinetics and pharmacodynamics in the plasma and interstitium with one state-dependent function:

$$
\begin{gathered}
\dot{G}=-p_{G} G(t)-S_{I} G(t) \frac{Q(t)}{1+\alpha_{G} Q(t)}+\frac{\min \left(d_{2} P_{2}, P_{\text {max }}\right)+E G P_{b}-C N S+P N(t)}{V_{g}} \\
\dot{I}=-\frac{n_{L} I(t)}{1+\alpha_{I} I(t)}-n_{K} I(t)-n_{I}(I(t)-Q(t))+\frac{u_{e x}(t)}{V_{I}}+\left(1-x_{L}\right) \frac{u_{e n}(G)}{V_{I}} \\
\dot{Q}=n_{I}(I(t)-Q(t))-n_{C} \frac{Q(t)}{1+\alpha_{G} Q(t)} \\
\dot{P}_{1}=-d_{1} P_{1}+P(t) \\
\dot{P}_{2}=-\min \left(d_{2} P_{2}, P_{\text {max }}\right)+d_{1} P_{1} \\
u_{e n}(G)=\max \left(16.67, \frac{14 G(t)}{1+0.0147 G(t)}-41\right)
\end{gathered}
$$


Where $G(t)[\mathrm{mmol} / \mathrm{L}]$ is the total plasma glucose, $I(t)[\mathrm{mU} / \mathrm{L}]$ is the plasma insulin and interstitial insulin is represented by $Q(t)$ [mU/L]. Exogenous insulin input is represented by $u_{e x}(t)[\mathrm{mU} / \mathrm{min}]$ and endogenous insulin production is estimated with $u_{e n}[\mathrm{mU} / \mathrm{min}]$, modelled as a function of plasma glucose concentration determined from critical care patients with a minimum pancreatic output of $1 \mathrm{U} / \mathrm{hr} . P_{1}[\mathrm{mmol}]$ represents the glucose in the stomach and $P_{2}$ [mmol] represents glucose in the gut. Enteral glucose input is denoted $P(t)$ [mmol/min]. Table 1 shows the major components and constants of the model defined in Equations 1-5. A graphical overview is presented in Figure 1.

Table 1: Constants and identified parameter ranges in the ICING model of Equations 1 - 6

\begin{tabular}{|c|c|c|}
\hline $\begin{array}{l}\text { Model } \\
\text { variable }\end{array}$ & $\begin{array}{l}\text { Numerical value (or typical } \\
\text { range) }\end{array}$ & Definition \\
\hline$p_{G}$ & $0.006 \mathrm{~min}^{-1}$ & endogenous glucose clearance \\
\hline$S_{I}$ & {$\left[1 \times 10^{-7}-1 \times 10^{-2}\right] \mathrm{L} /(\mathrm{mU} . \mathrm{min})$} & insulin sensitivity \\
\hline$\alpha_{G}$ & $1 / 65 \mathrm{~L} / \mathrm{mU}$ & $\begin{array}{l}\text { saturation of insulin-dependent glucose clearance and receptor- } \\
\text { bound insulin clearance from interstitium }\end{array}$ \\
\hline$d_{1}$ & $-\ln (0.5) / 20$ & rate of glucose transfer between the stomach and gut \\
\hline$d_{2}$ & $-\ln (0.5) / 100$ & rate of glucose transfer from the gut to the bloodstream \\
\hline$E G P_{b}$ & $1.16 \mathrm{mmol} / \mathrm{min}$ typically & $\begin{array}{l}\text { Basal endogenous glucose production (unsuppressed by glucose } \\
\text { and insulin concentration) }\end{array}$ \\
\hline$C N S$ & $0.3 \mathrm{mmol} / \mathrm{min}$ & $\begin{array}{l}\text { non-insulin mediated glucose uptake by the central nervous } \\
\text { system }\end{array}$ \\
\hline$V_{G}$ & $13.3 \mathrm{~L}$ & glucose distribution volume \\
\hline$P_{\max }$ & $6.11 \mathrm{mmol} / \mathrm{min}$ & Maximum disposal rate from the gut \\
\hline$n_{I}, n_{c}$ & $0.0075 \mathrm{~min}^{-1}$ & $\begin{array}{l}\text { rate of transport between plasma and interstitial insulin } \\
\text { compartments }\end{array}$ \\
\hline$\alpha_{I}$ & $1.7 \times 10^{-3} \mathrm{~L} / \mathrm{mU}$ & saturation of plasma insulin clearance by the liver \\
\hline$V_{I}$ & $4.0 \mathrm{~L}$ & insulin distribution volume \\
\hline$x_{L}$ & 0.67 & First-pass hepatic insulin clearance \\
\hline$n_{K}$ & $0.0542 \mathrm{~min}^{-1}$ & clearance of insulin from plasma via the renal route \\
\hline$n_{L}$ & $0.1578 \mathrm{~min}^{-1}$ & clearance of insulin from plasma via the hepatic route \\
\hline
\end{tabular}




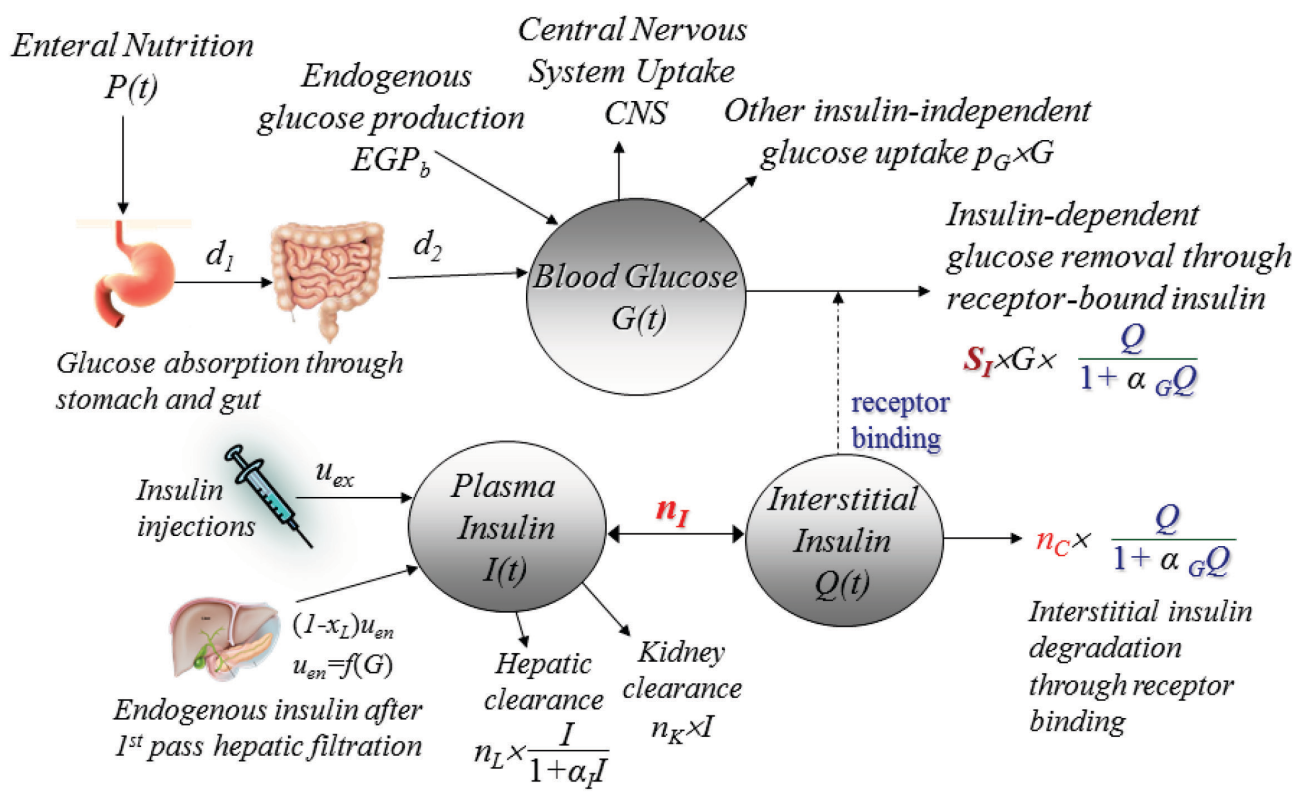

Figure 1: ICING model schematic overview

\subsection{Glargine Compartment Model}

The Glargine Compartment model captures the kinetics of Glargine from injection to appearance in plasma. Glargine has four states: precipitate, hexameric, monomeric / dimeric, and local interstitium. Figure 2 shows the interaction of these states $[18,19]$. The resulting compartment model is defined:

\section{$\underline{\text { Precipitate State }}$}

$$
\begin{gathered}
\dot{p}_{g l a}(t)=\frac{-k_{\text {prep,gla }} p_{\text {gla }}(t)}{1+\frac{k_{\text {prep,gla }}}{r_{\text {dis,max }}} p_{\text {gla }}(t)}+u_{p, g l a}(t) \\
\boldsymbol{u}_{\boldsymbol{p}, \boldsymbol{g l a}}(\boldsymbol{t})=\boldsymbol{\alpha}_{\text {gla }} \boldsymbol{u}_{\text {total,gla }}(\boldsymbol{t})
\end{gathered}
$$

$\underline{\text { Hexameric State }}$

$$
\begin{gathered}
\dot{x}_{h, g l a}(t)=-\left(k_{1, g l a}+k_{d}\right) x_{h, g l a}(t)+\frac{k_{\text {prep }, \text { gla }} p_{\text {gla }}(t)}{1+\frac{k_{\text {prep }, \text { gla }}}{r_{\text {dis,max }}} p_{\text {gla }}(t)} \\
u_{h, \text { gla }}(t)=u_{\text {total,gla }}(t)\left(1-\alpha_{g l a}\right)-u_{m, g l a}(t)
\end{gathered}
$$


$\underline{\text { Dimeric/Monomeric State }}$

$$
\dot{x}_{d m}(t)=-\left(k_{2}+k_{d}\right) x_{d m}(t)+k_{1, g l a} x_{h, g l a}(t)+u_{m, g l a}(t)
$$

$\underline{\text { Interstitium }}$

$$
\dot{x}_{i}(t)=-\left(k_{3}+k_{d i}\right) x_{i}(t)+k_{2} x_{d m}(t)
$$

Where $p_{\text {gla }}(t)[\mathrm{mU}]$ is the total Glargine in precipitate form, $x_{h, g l a}(t)[\mathrm{mU}]$ is the total Glargine in hexameric form, $x_{d m}(t)[\mathrm{mU}]$ is the total Glargine in monomeric / dimeric form and $x_{i}(t)$ $[\mathrm{mU}]$ is the total Glargine in the (local) interstitium. The exogenous Glargine is represented by $u_{p, g l a}(t)[\mathrm{mU}]$ in the precipitate form, $u_{m, g l a}(t)$ in the monomeric / dimeric form and $u_{h, g l a}(t)$ in the hexameric form. All other terms and values are defined in Table 2, based on an extensive validation study $[18,19]$.

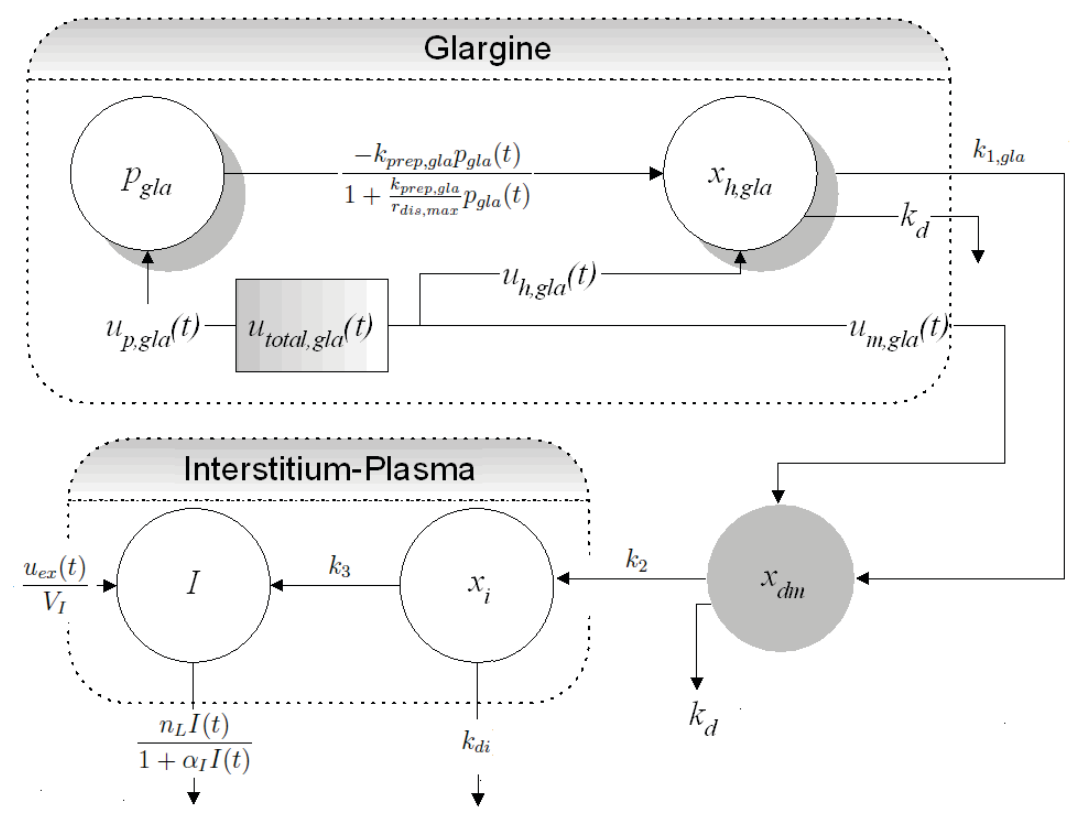

Figure 2: Glargine Compartment Model Overview 
Table 2: Constants and definitions in the Glargine compartment model

\begin{tabular}{|c|c|c|c|}
\hline $\begin{array}{c}\text { Model } \\
\text { Variable }\end{array}$ & \multicolumn{2}{|c|}{ Numerical Value } & Description \\
\hline$k_{\text {prep }, \text { gla }}$ & 0.0216 & {$\left[\mathrm{~min}^{-1}\right]$} & Glargine precipitate dissolution rate \\
\hline alphagla & 0.9462 & & Fraction of glargine as precipitate \\
\hline$k_{l, g l a}$ & 0.0062 & {$\left[\mathrm{~min}^{-1}\right]$} & Hexamer dissociation rate \\
\hline$D$ & $9.00 \times 10^{-5}$ & {$\left[\mathrm{~cm}^{2} / \mathrm{min}\right]$} & Diffusion constant for hexameric and dimeric/monomeric states \\
\hline$k_{2}$ & 0.0106 & {$\left[\min ^{-1}\right]$} & Dimeric/monomeric insulin transport rate into interstitium \\
\hline$k_{3}$ & 0.0618 & {$\left[\mathrm{~min}^{-1}\right]$} & Interstitium transport rate into plasma \\
\hline$k_{d i}$ & 0.029 & {$\left[\mathrm{~min}^{-1}\right]$} & Rate of loss from interstitium \\
\hline$V_{x}$ & 11.38 & {$[\mathrm{~L}]$} & Subcutaneous insulin distribution volume \\
\hline$B_{r_{-} \text {dismax }}$ & 2.3134 & {$[\mathrm{mU} / \mathrm{min}]$} & Baseline glargine precipitate dissolution rate \\
\hline$Q_{D}$ & $1.50 \times 10^{-2}$ & {$\left[\mathrm{ml}^{2} / \mathrm{mU}^{2}\right]$} & Hexameric-dimeric equilibrium constant \\
\hline$U_{\text {tres }}$ & $2.01 \times 10^{3}$ & {$[\mathrm{mU}]$} & Dosage threshold \\
\hline
\end{tabular}

Glargine release from precipitate to hexameric form is a saturable process. The maximum dissolution rate, $r_{d i s, \max }[\mathrm{mU} / \mathrm{min}]$, gives Glargine its unique kinetic profile and is defined:

$$
r_{\text {dis,max }}=B r_{d i s, \text { max }}\left(\alpha_{\text {gla }} u_{\text {total,gla }}<U_{\text {tres }}\right)+\frac{B r_{\text {dis,max }} \alpha_{\text {gla }} u_{\text {total,gla }}}{U_{\text {tres }}}\left(\alpha_{\text {gla }} u_{\text {total,gla }} \geq U_{\text {tres }}\right)
$$

where $B r_{\text {dis,max }}[\mathrm{mU} / \mathrm{min}]$ is the baseline precipitate dissolution rate and $U_{\text {tres }}[\mathrm{mU}]$ is the dosage threshold. The volume of the Glargine injected also has an effect on the kinetics in the form of a diffusive loss from the hexameric and monomeric /dimeric states. The rate of this diffusive loss $k_{d}\left[\mathrm{~min}^{-1}\right]$ is defined:

$$
\begin{gathered}
k_{d}=\frac{3 D}{r} \\
r=\left(\frac{3 V_{i n j}}{4 \pi}\right)^{1 / 3}
\end{gathered}
$$

where $r[\mathrm{~cm}]$ is the radius of the depot formed by the subcutaneous injection and $D\left[\mathrm{~cm}^{2} / \mathrm{min}\right]$ is the diffusion constant for the hexameric and monomeric /dimeric states. 
Finally the initial quantity of the Dimeric/Monomeric state in solution is found by solving the following derived from [19]:

$$
Q_{D} V_{i n j}\left(\frac{U_{m}}{V_{i n j}}\right)^{3}+u_{m}-u_{t o t a l}\left(1-\alpha_{g l a}\right)=0
$$

\section{$\underline{2.3 \text { Control Approach }}$}

The main goal is to develop a robust and safe controller to investigate the efficacy and variability in Glargine kinetics, without degrading control quality or safety from hypoglycemia. The main issues are the potential variation in Glargine efficacy $(1.0-2.0 \mathrm{x})$, the periods of low insulin appearance at the start and end of Glargine's 22-26 hour action period, and the need to modulate nutrition rates during Glargine administration for safety and performance because insulin administration is determined solely by Glargine appearance.

There is evidence suggesting that Glargine may be to be up to 2 times as effective as regular insulin, partly attributed to a more effective bonding to the IGF-I receptor [22]. Hence, this study assumes an estimated Glargine efficacy factor of 1.5 for design, in the absence of other data. Each resulting controller was then tested with efficacy factors of 1.0, 1.5 and 2.0. If a controller provided a satisfactory level of control for all three efficacies then it was deemed safe and robust to this variable.

Although Glargine has a relatively flat action profile that acts over a 22-26 hour period [23], 3-6 hours is required before a significant appearance of insulin is observed in plasma, resulting in a period of low insulin appearance immediately after Glargine is administered. A 
similar phenomenon occurs at the end of the 22-26 hour period. For this trial design, the STAR protocol [21] is assumed running during the first and last 4 or 6 hours of the estimated 24-hour period after Glargine is administered to supplement Glargine appearance with IV insulin, as it is the current standard of care in Christchurch Hospital.

To best observe the effects of Glargine, a period of Glargine as the only exogenous insulin is desired to eliminate other factors. However, longer periods increase the potential for control degradation. During the 16-hour peak of Glargine action, no exogenous insulin is administered, during which glycemic control is achieved only by modulating nutrition administration rates. The results will allow determination of Glargine efficacy and kinetics for each patient, and thus their variability across a test cohort.

BG measurements are intended to be taken hourly during the 24-hour trials to ensure safety. However, for in-silico virtual trials, 2 and 3-hourly BG measurements are used for the Glargine isolation period to illustrate the potential to reduce clinical effort.

Glargine bolus size was based on the total insulin previously administered to the patient, as a simple and easily calculated bedside metric. The sum over the previous 12,18 and 24 hours before the Glargine is administered was tested. Values less than the 24-hour sum reflect both safety concerns over efficacy, as well as the tendency for stable patients to improve and require increasingly less insulin [15]. 
STAR [21] targets a forecasted $5^{\text {th }}$ and $95^{\text {th }}$ percentile glucose values to specified BG ranges. During the 16 hour Glargine isolation period this BG target places the $95^{\text {th }}$ percentile BG outcome on $8 \mathrm{mmol} / \mathrm{L}$, otherwise the $5^{\text {th }}$ is placed on $4.4 \mathrm{mmol} / \mathrm{L}$. Figure 3 illustrates the stochastic bands used by STAR when recommending treatments. A, B, and C show the $5^{\text {th }}$ percentile of $\mathrm{BG}$ values for a given intervention and $\mathrm{D}, \mathrm{E}$, and $\mathrm{F}$ show the $95^{\text {th }}$ percentile $\mathrm{BG}$ value, for 1, 2 and 3-hourly predictions.

The lower BG target is $4.4 \mathrm{mmol} / \mathrm{L}$ with an upper tolerance of $1 \mathrm{mmol} / \mathrm{L}$ when a $5^{\text {th }}$ percentile BG outcome to low bound target is used. The upper BG target is $8.0 \mathrm{mmol} / \mathrm{L}$ with an upper tolerance of $1 \mathrm{mmol} / \mathrm{L}$ when a $95^{\text {th }}$ percentile $\mathrm{BG}$ outcome to high bound target is used in the Glargine isolation period. The tight control achieved with SPRINT (the standard protocol in the Christchurch ICU) is not expected with the SING controller due to the decreased interventions in the Glargine isolation period. Therefore, the large tolerance bands are chosen to ensure higher nutrition rates and loosen regulation for these less acute, stable wards.

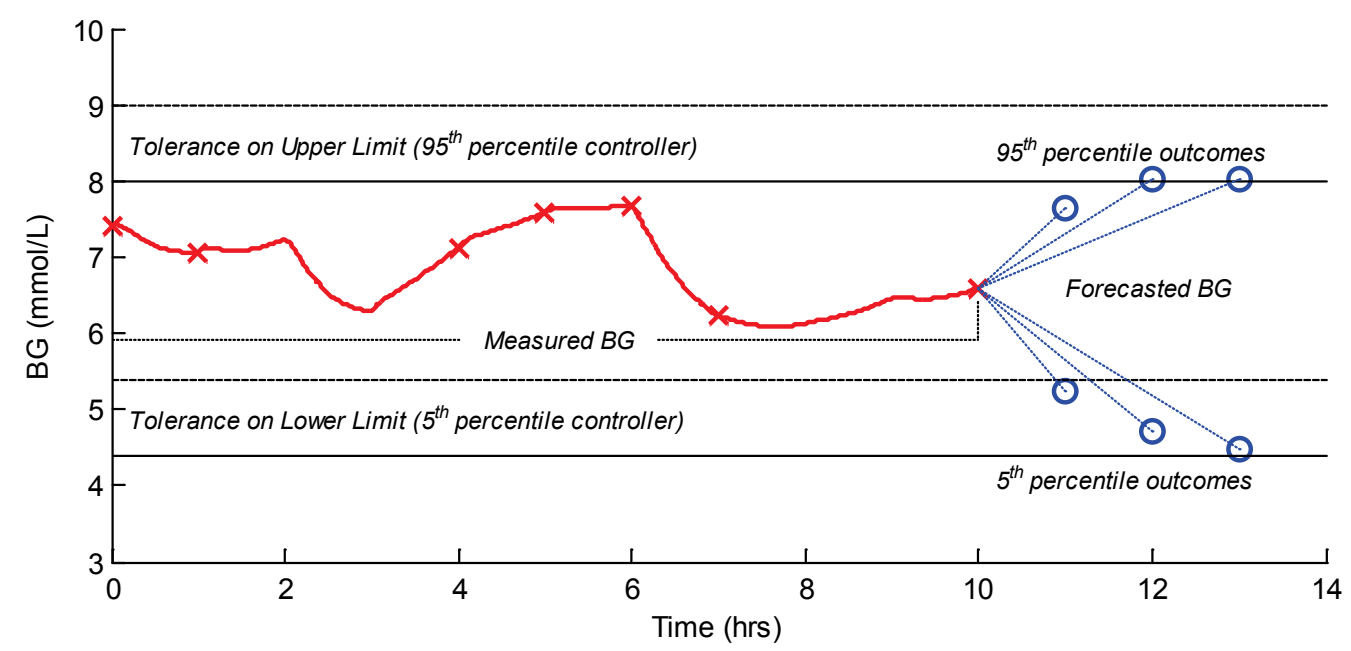

Figure 3: Schematic of control using stochastic forecasting showing a typical BG profile and 1-3 hour forecast BG bands. Target range of $4.4-8.0 \mathrm{mmol} / \mathrm{L}$ is shown with the $1 \mathrm{mmol} / \mathrm{L}$ tolerances used in the different controllers. 
The controller logic for targeting the $95^{\text {th }}$ percentile BG outcome is shown in Figure 4. It calculates the patient outcomes for nutrition at the highest allowed nutrition rate and attempts to target the $95^{\text {th }}$ percentile of BG outcomes to the upper target band. A check is made to ensure that the $5^{\text {th }}$ percentile of BG outcomes does not drop below the lower band. If an acceptable treatment is not found, the nutrition rate is reduced and the logic re-applied. For the in-silico virtual trials, 2 and 3 hourly measurements are permitted by running the logic in Figure 4 with 1, 2 and 3-hourly forecasts. Note that only nutrition can be modulated in this period to control glycemia once Glargine is given. Similar logic is used for the $5^{\text {th }}$ percentile controller.

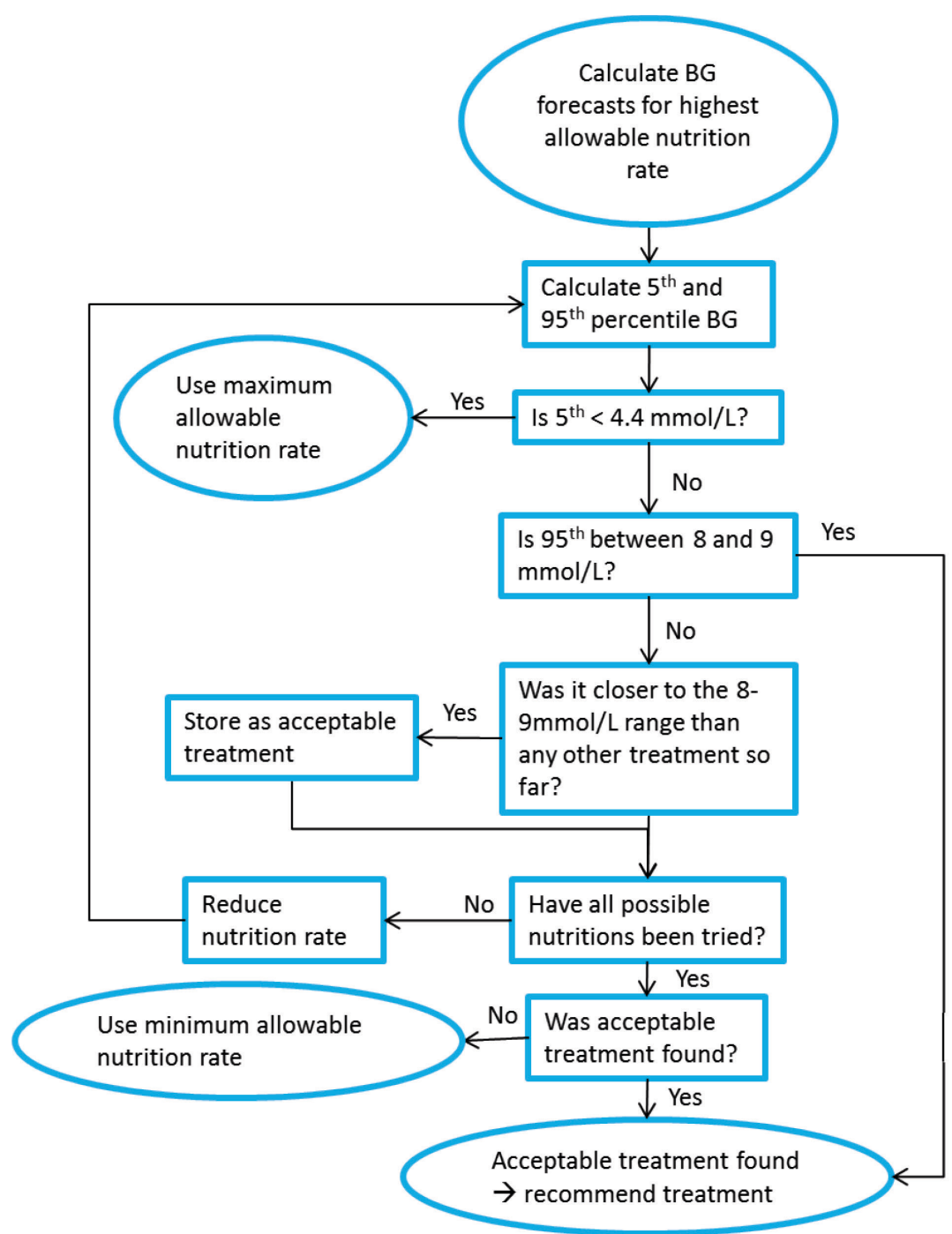

Figure 4: Controller logic. It modulates nutrition only and assumes insulin appearance based on the models of Equations 1-6 and 7-16 
The clinical trial design consists of:

- Glargine administered based on patient's previous insulin requirements

- STAR recommended insulin boluses administered on top of the Glargine at the start and end of the action profile. The $5^{\text {th }}$ percentile BG outcome to low bound target is used in this period.

- No exogenous IV insulin is recommended during the 16-hour peak Glargine appearance, $95^{\text {th }}$ percentile BG outcome to high bound target is used.

- BG measurements hourly for safety

Finally, a second controller, SING2, is designed specifically to demonstrate the potential reductions in effort if the efficacy of Glargine is known so that a more aggressive and lower clinical effort control method can be implemented safely. The SING2 controller's logic in this specific case is defined:

- Assumes Glargine efficacy of $1.5 \mathrm{x}$

- Glargine bolus size equal to the insulin administered over the previous 24 hours

- STAR recommended boluses on top of Glargine for all 24-hours

- $\quad 2$ and 3 hourly treatments permitted per STAR [21]

- $95^{\text {th }}$ percentile BG outcome is targeted to the high bound

- The upper tolerance band on the upper target is $1 \mathrm{mmol} / \mathrm{L}$

\section{$\underline{2.4 \text { Virtual Trials }}$}

Clinically validated virtual trials [16] were run on virtual patients made from retrospective clinical data. The virtual patients were created using the clinical data to create hourly insulin 
sensitivity profiles which are used to simulate the effects of different treatments on the patients.

The following virtual trials were run on the virtual patient cohort. Simulation outcomes for the 24 hour trials were used to verify performance both directly against SPRINT.

- Glargine bolus size equal to total insulin recommendations over the previous 12,18 and 24 hours. Each run at 1.0, 1.5 and $2.0 x$ efficacy with $95^{\text {th }}$ BG outcome targeted to the high bound during a Glargine isolation period of 16 hours

- Best performing Glargine bolus size with a Glargine isolation period of 12 hours at 1.0, 1.5 and $2.0 \mathrm{x}$ efficacy with $95^{\text {th }}$ BG percentile to high bound targeting during the isolation period

- Best performing controller logic with $5^{\text {th }}$ BG percentile to low bound targeting throughout

- Glargine bolus size equal to total insulin recommendations over the previous 12,18 and 24 hours at 1.5 efficacy with no Glargine isolation period and $95^{\text {th }}$ BG percentile to high bound targeting throughout

The outcomes are used to determine the most robust and safest dose and control response.

\section{$\underline{\text { 2.5 Performance Metrics }}$}

Results from the clinically validated in-silico virtual trials are compared to the original SPRINT clinical data to assess safety and performance. An overall increase in BG levels is expected as a result of decreased clinical intervention without increasing the risk of hypoglycemia. The performance of each controller was assessed by the following criteria: 
1. Effort: Number of nursing interventions from nutrition rate changes, insulin boluses and BG measurements

2. Performance: Measuring the percentage of $\mathrm{BG}$ between 4.0 and $8.0 \mathrm{mmol} / \mathrm{L}$

3. Nutrition: Enteral nutrition administration rates as a percentage of ACCP/SCCM goal rates [24]

4. Safety: Percentage of BG less than $4.0 \mathrm{mmol} / \mathrm{L}$

It is important to note that the figures for the number of BG measurements for the SING controller do not include those extra measurements taken hourly only for safety in planned clinical trials being designed.

\section{$\underline{\text { 2.6 Virtual Patients }}$}

The target patients for these trials are critically ill, but in a relatively stable state. Seventeen (of 391) patients from the SPRINT cohort [7] met the following stability criteria:

- Stable hourly insulin requirement of $\leq 3 \mathrm{U} / \mathrm{hr}$ of insulin, for at least 12 hours

- Stable nutrition rate of $\geq 60 \%$ of the calculated individual patient's goal rate, based on ACCP guidelines of $25 \mathrm{kcal} / \mathrm{kg} / \mathrm{hr}$ [24]

- No acute renal failure

- Less than $1000 \mathrm{ml}$ of fluid given as intravenous boluses in the past 24 hours, indicating hemodynamic or circulatory stability and a stable interstitial volume.

- Resolving multiple organ failure based on a Sequential Organ Failure Assessment $(\mathrm{SOFA})$ score $<6[25]$ 
For safety and to limit Glargine bolus size in this initial study an additional criterion was:

- Maximum total insulin requirement of $\leq 48 \mathrm{U}$, over the last 18 hours

These criteria define a set of patients who would be eligible for transfer to a HDU and a less intense AGC routine. The number (17) is low enough to create an initial protocol without excessive data, and other patients (of 391) might readily qualify. The total insulin dose criterion, chosen also for safety in planned clinical trials to limit dose, was a significant limiting factor for patient numbers. Table 3 presents the demographic details of the 17 patients.

Table 3: Patient Cohort

\begin{tabular}{ccccccc}
\hline Patient ID & LOS (hrs) & Medical Group & Apache II score & Age (years) & Sex & Mortality \\
\hline 5006 & 161 & Respiratory Failure & 23 & 44 & $\mathrm{~F}$ & $\mathrm{~N}$ \\
5033 & 100 & Trauma & 29 & 66 & $\mathrm{~F}$ & $\mathrm{~N}$ \\
5054 & 158 & Respiratory Failure & 18 & 75 & $\mathrm{M}$ & $\mathrm{N}$ \\
5060 & 271 & Gastrointestinal & 15 & 79 & $\mathrm{M}$ & $\mathrm{N}$ \\
5061 & 140 & Trauma & 16 & 22 & $\mathrm{M}$ & $\mathrm{N}$ \\
5076 & 240 & Gastrointestinal & 12 & 32 & $\mathrm{M}$ & $\mathrm{N}$ \\
5086 & 127 & Respiratory & 32 & 64 & $\mathrm{M}$ & $\mathrm{N}$ \\
5101 & 280 & Neurological & 19 & 50 & $\mathrm{~F}$ & $\mathrm{~N}$ \\
5122 & 159 & Trauma & 19 & 73 & $\mathrm{M}$ & $\mathrm{N}$ \\
5149 & 325 & Surgical & 21 & 60 & $\mathrm{M}$ & $\mathrm{N}$ \\
5207 & 155 & Respiratory & 19 & 42 & $\mathrm{~F}$ & $\mathrm{~N}$ \\
5279 & 85 & Septic Shock & 18 & 18 & $\mathrm{M}$ & $\mathrm{N}$ \\
5299 & 103 & Respiratory & 20 & 56 & $\mathrm{~F}$ & $\mathrm{~N}$ \\
5315 & 196 & Respiratory & 18 & 19 & $\mathrm{M}$ & $\mathrm{N}$ \\
5322 & 136 & Respiratory & 15 & 72 & $\mathrm{~F}$ & $\mathrm{~N}$ \\
5351 & 166 & Respiratory & 12 & 76 & $\mathrm{M}$ & $\mathrm{N}$ \\
5376 & 120 & Surgical & 16 & 56 & $\mathrm{~F}$ & $\mathrm{~N}$ \\
\hline Median & 158 & & 18 & $58 \%$ & $\mathrm{Male}$ &
\end{tabular}




\section{$\underline{\text { 3.0 Results }}$}

Table 4 shows the expected glycemic differences between Glargine dose sizes for the nominal $1.5 x$ efficacy. The sum over 18 hours was selected due to the safety limits imposed on the Glargine dosage, and it showed a balance of $\% \mathrm{BG}$ within the $4.0-8.0 \mathrm{mmol} / \mathrm{L}$ band and $\% \mathrm{BG}<4.0 \mathrm{mmol} / \mathrm{L}$, comparable to or better than SPRINT. While this choice reduced the number of nutrition changes required to maintain control using Glargine, it is evident that the fixed insulin dose requires greater nutrition adjustment compared to SPRINT, which used both in control.

Table 4: Comparison of SING with dosage based on 12, 18 and 24 hours at 1.5x efficacy with STAR used for the first and last 4 hours

\begin{tabular}{|l|r|r|r|r|}
\hline & 12 hour sum & 18 hour sum & 24 hour sum & SPRINT \\
\hline BG measurements & 258 & 260 & 266 & 267 \\
\hline Boluses administered & 112 & 113 & 112 & 311 \\
\hline Nutrition changes & 96 & 90 & 103 & 39 \\
\hline$\%$ BG within $4.0-8.0 \mathrm{mmol} / \mathrm{L}$ & 91.29 & 92.71 & 94.59 & 88.60 \\
\hline Median glucose rate (\%goal) & $100 \%$ & $100 \%$ & $100 \%$ & $90 \%$ \\
\hline$\%$ BG < 4.0 mmol/L & 1.41 & 2.35 & 4.71 & 11.16 \\
\hline Median Glargine Dose (U) [min max] & $18.0[6.0-30.0]$ & $24.0[6.0-48.0]$ & $36.0[6.0-72.0]$ & $\mathrm{N} / \mathrm{A}$ \\
\hline
\end{tabular}

Table 5 shows a comparison at 1.5x efficacy for STAR running for the first and last 4 or 6 hours of the 24 hours after Glargine is administered, as well as a comparison between if a $5^{\text {th }}$ percentile or $95^{\text {th }}$ percentile based targeting system is used. For a 4-hour STAR period (16h Glargine isolation) there was slightly poorer control compared to the 6-hour STAR period (12h Glargine isolation). However, the 4-hour STAR period still outperformed SPRINT and reduced mild hypoglycemia compared to the 6-hour STAR period. During the 16 hour Glargine isolation period there was a tendency for the controller to recommend lower nutrition rates for a $5^{\text {th }}$ percentile $\mathrm{BG}$ outcome to low bound targeting system. Hence a $95^{\text {th }}$ 
percentile BG outcome to high bound target was selected to meet clinical preferences for higher nutrition rates.

Table 5: Comparison of SING with 5th percentile BG outcome to low bound and 95th percentile to high bound and 4 hour and 6 hour STAR periods at 1.5x efficacy

\begin{tabular}{|c|c|c|c|c|}
\hline & SPRINT & $\begin{array}{l}4 \text { hour STAR period, } \\
95 \text { th percentile to } \\
\text { high bound }\end{array}$ & $\begin{array}{l}6 \text { hour STAR period, } \\
95 \text { th percentile to } \\
\text { high bound }\end{array}$ & $\begin{array}{l}4 \text { hour STAR period, } \\
5^{\text {th }} \text { percentile to low } \\
\text { bound }\end{array}$ \\
\hline BG measurements & 267 & 260 & 307 & 257 \\
\hline Boluses administered & 311 & 113 & 167 & 111 \\
\hline Nutrition changes & 39 & 90 & 80 & 116 \\
\hline $\begin{array}{l}\text { \% BG within } 4.0-8.0 \\
\mathrm{mmol} / \mathrm{L}\end{array}$ & 88.60 & 92.71 & 94.59 & 95.06 \\
\hline $\begin{array}{l}\text { Median glucose rate } \\
\text { (\%goal) }\end{array}$ & $90 \%$ & $100 \%$ & $100 \%$ & $70 \%$ \\
\hline$\% \mathrm{BG}<4.0 \mathrm{mmol} / \mathrm{L}$ & 11.16 & 2.35 & 4.00 & 3.06 \\
\hline
\end{tabular}

Based on these results, the final recommended SING controller comprises:

- Glargine bolus size equal to the insulin administered over the previous 18 hours

- STAR recommended boluses used for the first and last 4 hours of the 24 hour period after Glargine has been administered, 1 hour treatments only during this period.

- During the period where Glargine is the only form of exogenous insulin, the $95^{\text {th }}$ percentile BG outcome is targeted to the high bound, all other times the $5^{\text {th }}$ percentile BG outcome is targeted to the low bound

- The upper tolerance on the upper BG target is $1 \mathrm{mmol} / \mathrm{L}$

- Recommendations are made on the basis of a Glargine efficacy factor of 1.5 times

- Recommended dosage is rounded to the nearest $6 \mathrm{U}$ for clinical convenience 
Table 6 shows the final SING controller compared against SPRINT with varying efficacy levels. Figure 5 shows how BG varies for a representative patient for the 24-hour trial after an initial Glargine dose of $18 \mathrm{U}$. The varying efficacy and the relatively linear relation between BG and insulin efficiency is observed as expected. Safety was not compromised.

Table 6: Final SING Controller

\begin{tabular}{|l|r|r|r|r|}
\hline & SPRINT & \multicolumn{3}{|c|}{ SING } \\
\hline Efficacy: & - & $1.0 \mathrm{x}$ & $1.5 \mathrm{x}$ & $2.0 \mathrm{x}$ \\
\hline BG measurements & 267 & 269 & 260 & 254 \\
\hline Boluses administered & 311 & 114 & 113 & 110 \\
\hline Nutrition changes & 39 & 98 & 90 & 78 \\
\hline \% BG within 4.0 - 8.0 mmol/L & 88.60 & 87.76 & 92.71 & 94.12 \\
\hline Median glucose rate (\% goal) & $90 \%$ & $100 \%$ & $100 \%$ & $100 \%$ \\
\hline \% BG < 4.0 mmol/L & 11.16 & 1.65 & 2.35 & 4.24 \\
\hline
\end{tabular}

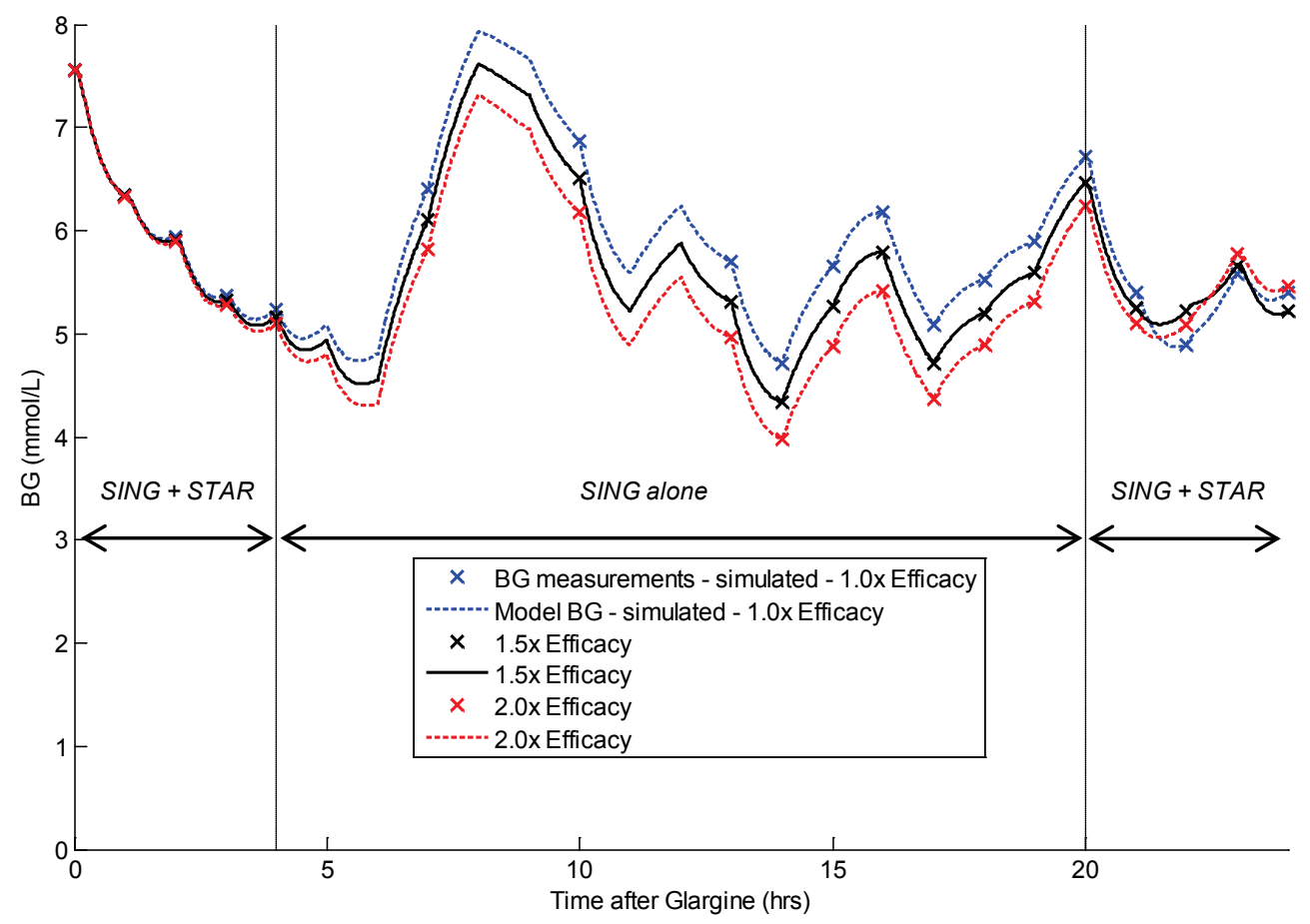

Figure 5: Patient 5299 - Effects of Efficacy 
The median nutrition rate is $100 \%$ of goal rate regardless of efficacy. The results show that adequate control is achieved for the case where Glargine is no more potent than regular insulin and control is improved for higher potencies of Glargine. However, for a higher potency, the risk of mild hypoglycemia increases, but even at the maximum suspected potency $(2.0 \mathrm{x})$ there is still a significant improvement over the SPRINT protocol. The cumulative frequency of BG levels in Figure 6 clearly shows robustness with a good balance of safety and performance. There is a significant reduction in $\% \mathrm{BG}<4.4 \mathrm{mmol} / \mathrm{L}$, and the relatively steep CDF slopes indicate the BG variability remains tightly controlled.

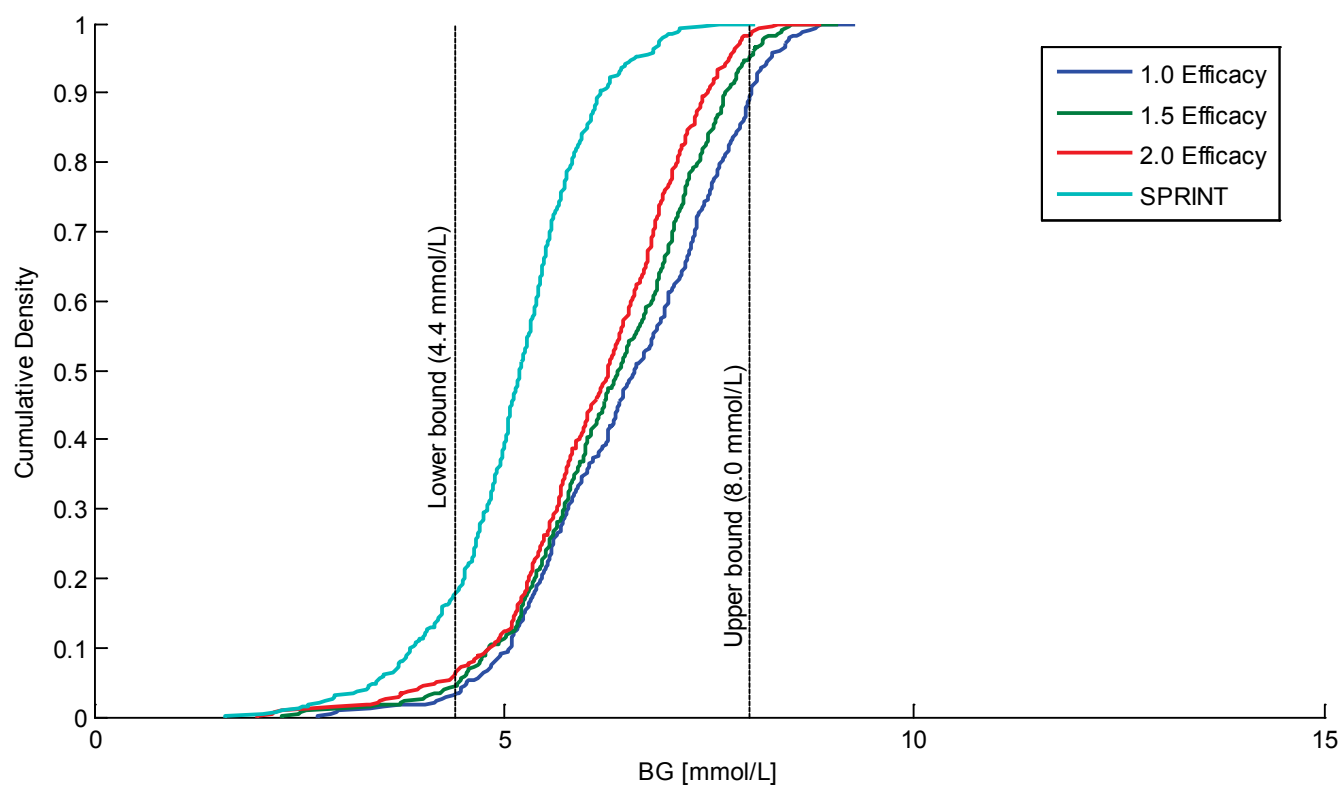

Figure 6: BG cumulative frequency for SING and SPRINT for all patients

The controller has been shown to be robust with perturbations made to the initial Glargine bolus size, based on prior insulin requirements. The results from altering the length of time that Glargine bolus sizes are based on show that, at worst (1.0x efficacy based on insulin requirements over 12 hours), control within the target band is $84.0 \%$. Safety is improved by using 1-hourly STAR treatments in conjunction with Glargine in the first and last 4-hours. 
The tight control achieved by the hourly STAR treatments has been proven to effectively control BG levels. Any unknown effects of Glargine will be compensated for with the model calculated insulin sensitivity. The small variance between the bands for varying efficacies in Figure 6 further indicates the robustness.

Table 7 shows an example the results from the SING2 controller, where it is assumed the efficacy is known to be 1.5. SING2 offers improved performance over SPRINT with increased nutrition delivery, patient safety, and time in desired band. A significant reduction in clinical effort is observed with a $27 \%$ reduction in BG measurements, a $59 \%$ reduction in insulin boluses and a $67 \%$ decrease in the number of nutrition changes required. Hence, if the efficacy is known reliably, then significant clinical effort reductions can be obtained with good performance and safety.

Table 7: SING2 for known Efficacy

\begin{tabular}{|l|r|r|r|}
\hline & SPRINT & SING2 & $\Delta \%$ \\
\hline BG measurements & 267 & 196 & $-27 \%$ \\
\hline Boluses administered & 311 & 129 & $-59 \%$ \\
\hline Nutrition changes & 39 & 13 & $-67 \%$ \\
\hline$\%$ BG within 4.0 - 8.0 mmol/L & 88.6 & 92.66 & $\begin{array}{r}+4.1 \% \\
\text { absolute }\end{array}$ \\
\hline Median glucose rate (\% goal) & $90 \%$ & $100 \%$ & $\begin{array}{r}+10 \% \\
\text { absolute }\end{array}$ \\
\hline$\%$ BG < 4.0 mmol/L & 11.16 & 4.82 & $\begin{array}{r}-6.3 \% \\
\text { absolute }\end{array}$ \\
\hline
\end{tabular}




\subsection{Discussion:}

The simulation results for the SING controller and its variations show that it is a robust and safe initial protocol to investigate the safety and performance of Glargine in this cohort to reduce clinical effort and transition stable patients to subcutaneous delivery. A possible limitation of this study is the low number of virtual patients included in the cohort. SPRINT is used on a cohort from which such patients may come, but initial selection criteria may have been too strict. However, the cohort selected does fairly represent a combination of genders, medical conditions and age. A larger cohort of suitable patients, preferably in clinical testing, would enable a greater statistical validity of the results. However the results presented justify clinical testing to prove the concept.

The unknown efficacy of Glargine requires specific measures to reduce patient risk in these trials. Hence, a noticeable decrease in clinical effort is not observed for SING in these proposed trials. Even though there is a significant reduction in insulin boluses administered there is a significant increase in the number of nutrition changes required. However, the SING2 controller showed the potential reductions available if the efficacy is more reliably known. Highly patient-specific or variable efficacy discovered in the clinical trials designed here would thus create significant issues affecting the feasibility of using Glargine consistently in large cohorts of this type if reduction of effort is a major criterion.

In long term applications of Glargine over multiple days the periods of low insulin appearance in plasma during the Glargine's action will not be an issue if the kinetics and efficacy of Glargine is known. A protocol can be designed such that the Glargine profiles 
overlap to minimise periods of low insulin appearance. This outcome is achieved by administering smaller doses more frequently than 24 hours.

A limitation of this trial design is that the effect of Glargine build up over days is not observed. Build up can occur if Glargine is present for more than 24 hours [26]. Simulation results for a single isolated dose of Glargine suggested that the build up of Glargine in the interstitial insulin compartment was not a significant issue. However, this behaviour has been observed clinically and may still play a role. The increase in interstitial insulin concentration was $4.6 \%$ of the initial value after 24 hours and $2.5 \%$ after 26 hours. Hence, over several days, this issue may not be a major factor given measurement and other errors that also contribute to the overall variation in control.

Finally, the goal of the controller was to investigate the kinetics and dynamics of Glargine. It is likely this information will be achieved through analysis of model-based $\mathrm{S}_{\mathrm{I}}$ as the patient transitions to/from the Glargine only period. If (for example) SI shows a general increase or decrease over the Glargine period that is resolved with the reintroduction of IV insulin it would infer values for Glargine potency. During the Glargine only period nutrition rates may be modified. 


\section{$\underline{5.0 \text { Conclusions }}$}

This paper presents an investigation into the use of Glargine in AGC for low effort controllers. A robust clinical trial has been designed to safely investigate the efficacy and kinetics of Glargine, prior to developing a final protocol. If the results of this trial verify the efficacy and kinetics of Glargine in critically ill patients, a low effort controller can be implemented to extend AGC to the HDU. It remains for clinical testing to determine interand intra- patient variability, thus determining the overall potential for using Glargine in large cohorts of HDU patients and stable ICU patients.

Overall, the results demonstrate the concept and potential to justify pilot clinical trials. Equally they clearly and safely highlight, in-silico, some issues with subcutaneous long acting insulin that may not otherwise have arisen until clinical testing. Hence, these outcomes should be prospectively tested. 


\subsection{References}

1. Capes SE, Hunt D, Malmberg K, Gerstein HC: Stress hyperglycemia and increased risk of death after myocardial infarction in patients with and without diabetes: a systematic overview. Lancet 2000, 355(9206):773-778.

2. Krinsley JS: Association between hyperglycemia and increased hospital mortality in a heterogeneous population of critically ill patients. Mayo Clin Proc 2003a, 78(12):1471-1478.

3. Ousman Y: Hyperglycemia in the Hospitalized Patient. Clinical Diabetes 2002, 20(3):147148.

4. Marfella R, Siniscalchi M, Esposito K, Sellitto A, De Fanis U, Romano C, Portoghese M, Siciliano S, Nappo F, Sasso FC et al: Effects of stress hyperglycemia on acute myocardial infarction: role of inflammatory immune process in functional cardiac outcome. Diabetes Care 2003, 26(11):3129-3135.

5. Griesdale DE, de Souza RJ, van Dam RM, Heyland DK, Cook DJ, Malhotra A, Dhaliwal R, Henderson WR, Chittock DR, Finfer $S$ et al: Intensive insulin therapy and mortality among critically ill patients: a meta-analysis including NICE-SUGAR study data. CMAJ 2009, 180(8):821-827.

6. Krinsley JS: Decreased mortality of critically ill patients with the use of an intensive glycemic management protocol. Crit Care Med 2003b, 31:A19.

7. Chase JG, Shaw G, Le Compte A, Lonergan T, Willacy M, Wong X-W, Lin J, Lotz T, Lee D, Hann $C$ : Implementation and evaluation of the SPRINT protocol for tight glycemic control in critically ill patients: a clinical practice change. Critical Care 2008, 12(2):R49.

8. Brunkhorst FM, Engel C, Bloos F, Meier-Hellmann A, Ragaller M, Weiler N, Moerer O, Gruendling $\mathrm{M}$, Oppert $\mathrm{M}$, Grond $\mathrm{S}$ et al: Intensive insulin therapy and pentastarch resuscitation in severe sepsis. N Engl J Med 2008, 358(2):125-139.

9. Finfer S, Chittock DR, Su SY, Blair D, Foster D, Dhingra V, Bellomo R, Cook D, Dodek P, Henderson WR et al: Intensive versus conventional glucose control in critically ill patients. N Engl J Med 2009, 360(13):1283-1297.

10. Preiser JC, Devos P: Clinical experience with tight glucose control by intensive insulin therapy. Crit Care Med 2007, 35(9 Suppl):S503-507.

11. Aragon D: Evaluation of nursing work effort and perceptions about blood glucose testing in tight glycemic control. Am J Crit Care 2006, 15(4):370-377.

12. Campbell RK, White JR, Levien T, Baker D: Insulin glargine. Clinical Therapeutics 2001, 23(12):1938-1957.

13. Schmeltz LR, DeSantis AJ, Schmidt K, O'Shea-Mahler E, Rhee C, Brandt S, Peterson S, Molitch $M E$ : Conversion of intravenous insulin infusions to subcutaneously administered insulin glargine in patients with hyperglycemia. Endocr Pract 2006, 12(6):641-650.

14. Heinemann L, Linkeschova R, Rave K, Hompesch B, Sedlak M, Heise T: Time-action profile of the long-acting insulin analog insulin glargine (HOE901) in comparison with those of NPH insulin and placebo. Diabetes Care 2000, 23(5):644-649.

15. Chase JG, Le Compte AJ, Suhaimi F, Shaw GM, Lynn A, Lin J, Pretty CG, Razak N, Parente JD, Hann CE et al: Tight glycemic control in critical care - The leading role of insulin sensitivity and patient variability: A review and model-based analysis. Computer Methods and Programs in Biomedicine 2011, 102(2):156-171.

16. Chase JG, Suhaimi F, Penning S, Preiser JC, Le Compte AJ, Lin J, Pretty CG, Shaw GM, Moorhead KT, Desaive T: Validation of a model-based virtual trials method for tight glycemic control in intensive care. Biomed Eng Online 2010, 9:84.

17. Lin J, Razak, N., Pretty, C., Le Compte, A., Docherty, P., Parente, J., Shaw, G., Hann, C., and Chase, J.: A physiological intensive control insulin-nutrition-glucose (icing) model validated in critically ill patients. Computer Methods and Program in Biomedicine 2010. 
18. Wong X, Chase J, Hann C, Shaw G, Lotz T, Lin J, Le Compte A: A Subcutaneous Insulin Pharmacokinetic Model for Computer Simulation in a Diabetes Decision Support Role: Validation and Simulation. Journal of Diabetes Science and Technology (JoDST) 2008b, 2(4):672-680.

19. Wong X, Chase J, Hann C, Shaw G, Lotz T, Lin J, Le Compte A: A Subcutaneous Insulin Pharmacokinetic Model for Computer Simulation in a Diabetes Decision Support Role: Model Structure and Parameter Identification. Journal of Diabetes Science and Technology (JoDST) 2008a, 2(4):658-671.

20. Razak N: Robust Modelling of the Glucose-Insulin System for Tight Glycemic Control of Less Critical Care Patients. PhD thesis. University of Canterbury; 2011.

21. Evans A, Shaw GM, Compte AL, Tan C-S, Ward L, Steel J, Pretty CG, Pfeifer L, Penning S, Suhaimi F et al: Pilot proof of concept clinical trials of Stochastic Targeted (STAR) glycemic control. Annals of Intensive Care 2011, 1(38).

22. Varewijck AJ, Goudzwaard JA, Brugts MP, Lamberts SW, Hofland LJ, Janssen JA: Insulin glargine is more potent in activating the human IGF-I receptor than human insulin and insulin detemir. Growth Horm IGF Res 2010, 20(6):427-431.

23. Lepore M, Pampanelli S, Fanelli C, Porcellati F, Bartocci L, Di Vincenzo A, Cordoni C, Costa E, Brunetti P, Bolli GB: Pharmacokinetics and pharmacodynamics of subcutaneous injection of long-acting human insulin analog glargine, NPH insulin, and ultralente human insulin and continuous subcutaneous infusion of insulin lispro. Diabetes 2000, 49(12):2142-2148.

24. Cerra FB, Benitez MR, Blackburn GL, Irwin RS, Jeejeebhoy K, Katz DP, Pingleton SK, Pomposelli J, Rombeau JL, Shronts E et al: Applied nutrition in ICU patients. A consensus statement of the American College of Chest Physicians. Chest 1997, 111(3):769-778.

25. Vincent JL, Moreno R, Takala J, Willatts S, De Mendonca A, Bruining H, Reinhart CK, Suter PM, Thijs LG: The SOFA (Sepsis-related Organ Failure Assessment) score to describe organ dysfunction/failure. On behalf of the Working Group on Sepsis-Related Problems of the European Society of Intensive Care Medicine. Intensive Care Med 1996, 22(7):707-710.

26. Lin J, Razak N, Chase JG, Wong J, Pretty C, Parente J, Le Compte A, Suhaimi F, Shaw G, Hann C: The Effect of Glargine as Basal Insulin Support for Recovering Critically III and High Dependency Unit Patients: An In-silico Study. In: 7th IFAC Symposium on Modelling in Control in Biomedical Systems: 2009; Aalborg, Denmark; 2009. 